\title{
Oesophageal cancer: an overview of a deadly disease
}

\begin{abstract}
R.E. White MD, MPH, FACS, Chief of Surgery and Endoscopy, Tenwek Hospital, P.O. Box 39, Bomet, Kenya and Clinical Associate Professor of Surgery, Brown University School of Medicine, Providence, RI, USA, R.K. Parker, BS
\end{abstract}

Correspondence to:

Dr. R.E. White, Tenwek Hospital, P.O. Box 39, Bomet, Kenya

\section{Summary}

Oesophageal cancer (OC) is one of the deadliest cancers in the world. Although it affects many people throughout East Africa, relatively little work has been done to fully understand this disease. This review addresses recent changes in the understanding of $\mathrm{OC}$ from a global perspective, with special attention given to OC in Kenya.

\section{Epidemiology}

Oesophageal cancer is the eighth most common cancer worldwide, and the sixth most common cause of death from cancer. From a worldwide perspective, one of the most striking features of oesophageal cancer is the extreme geographic variation in incidence. At a global level, a 20-fold difference is seen in official statistics between high-risk and low risk areas (1). This difference becomes even more striking when one looks at specific high-risk areas within certain countries. For example, while the incidence annually among women in North America is close to 2 cases per 100,000 population, the incidence among women in Iran has historically been estimated to be close to 100 times higher, and the annual death rate for OC in Linxian, People's Republic of China exceeds 100 deaths per 100,000 population $(1,2)$. One therefore needs really to consider areas where $\mathrm{OC}$ is endemic separately from non-endemic areas. Those areas in which OC should be considered endemic are listed in Table 1. It should be noted that even within these "hotspots" of OC, there is extreme variation within relatively short geographic distances (1-3).

The vast majority of oesophageal cancer consists of either oesophageal squamous cell carcinoma (OSCC), or adenocarcinoma (AC) (5). Other malignancies constituting less than $1 \%$ of total oesophageal malignancies include small cell carcinoma, melanoma, malignant mesenchymal tumours (including Kaposi's Sarcoma), and lymphomas. From a global perspective, OSCC accounts for approximately $80 \%$ of OC, and is clearly the predominant type in endemic areas $(1,2,4,5)$. OSCC tends to occur more commonly among the black population (6), while AC is increasing among the white population in nonendemic areas (7). While OC in general tends to be a male dominated disease (male:female ratio of 5-7:1), a common finding in endemic areas is a more evenly distributed incidence between genders, with male:female ratios of 1-2:1 $(1,4,5)$. In many western countries, $\mathrm{AC}$ is increasing rapidly, and the incidence has surpassed that of OSCC. In the USA, for example, AC overtook OSCC as the predominant type in the late 1980's and is now three times more common than OSCC, increasing at a rate of 5\%-10\% per year, making it the fastest growing cancer incidence rate in the country (7). One must bear in mind that the absolute numbers still remain relatively small compared to endemic areas. The overall incidence of OC continues to rise, with most of 
the increase due to the rise of $\mathrm{AC}$ in non-endemic areas (8). Average age at diagnosis of OC tends to be in the 50's and 60's, with AC presenting in patients about 10 years older than in OSCC (9). However, in some endemic areas, this may vary considerably. White et al reported in 2002 that in an endemic area of Kenya, $11 \%$ of all patients with OC were 30 years of age or less (5).

Overall survival from OC remains low and varies somewhat between geographic locations, with 5 year survival in the USA approximately $16 \%$, while in Europe it is $10 \%(10,11)$. This difference is probably largely due to differences in stage at diagnosis.

There does not seem to be significant survival differences between endemic and nonendemic areas when differences in treatment options and availability are considered. While in China, the survival is essentially equal to that of the USA, survival in Africa tends to be lower. However, in a case series of surgically treated patients in East Africa, overall median survival of 24 months was reported $(12,13)$. A great deal of debate centers around whether or not OSCC and AC have different survival patterns. Evidence can be found in the literature for increased survival with either OSCC or AC $(14,15)$. It is a complex issue, however the truth may be more reflective of differences in regional access to health care and variable comorbidities than in actual survival differences between OSCC and AC.

\section{Table 1: Geographic areas of endemic oesophageal cancer}

\section{China}

Eastern Africa

Japan (males only)

Northern Italy

Northwestern France

Southern Africa

Southwestern Asia (particularly Iran, Kazakhstan, and Turkey)

\section{Pathogenesis/ Risk Factors}

While there are significant differences between AC and OSCC, there appears to be a common final pathway of progression from dysplasia (mild, moderate and severe), to mucosal cancer to invasive carcinoma. While mild dysplasia seems to frequently spontaneously regress, the finding of moderate or severe dysplasia appears to be much more predictive of the development of frank carcinoma. The primary risk factor for the development of AC appears to be gastro-oesophageal reflux disease (GORD) with subsequent development of Barrett's oesophagus (BO) and Barrett's dysplasia. These and other risk factors for the development of OC are summarized in Table 2.

\section{Clinical Presentation/ Diagnosis}

For the majority of patients, $\mathrm{OC}$ is discovered in one of two ways. The first, and by far the most common course throughout the world, is for patients to present with symptoms usually indicative of advanced lesions. Secondly, patients may present with early lesions discovered through surveillance programs for patients with GORD, or after endoscopy for non-specific dyspepsia. These two presentations will be discussed separately.

Throughout most of the world, most patients present to health care personnel only after symptoms of OC develop. The nature of OC is such that symptoms generally do not develop until a significant portion of the oesophageal lumen is obstructed. Since intra-lumenal growth is a relatively late phenomenon in the course of the disease, these patients present with advanced disease, often with large primary tumours, regional lymph node involvement, and distant metastases. The most common presenting symptoms are dysphagia and weight loss, both of which are late symptoms. Dysphagia has been reported to occur only after the tumour encroaches on $75 \%-90 \%$ of the oesophageal circumference (36). In the author's institution where 200-300 new cases of OC are seen annually-nearly all patients present with significant dysphagia. Endoscopic dilation is required in approximately $95 \%$ of cases simply to allow passage of the endoscope (personal data). Interestingly, most patients can accurately describe the level of their obstruction (upper, 
mid, or lower oesophagus) based upon their symptoms. Odynophagia, vomiting, chest pain, and hematemesis are less common presenting symptoms $(4,37)$. Cough productive of purulent sputum, particularly occurring immediately after oral intake, is highly suggestive of malignant tracheooesophageal fistula. Hoarseness of the voice is also a particularly ominous symptom, as this most often indicates recurrent laryngeal nerve involvement, or occasionally direct involvement of the larynx. A small percentage of relatively earlier lesions will present after food bolus obstruction of the oesophagus. After clearing of the obstruction (either spontaneously or via intervention), follow-up studies may reveal the presence of a non-obstructing oesophageal lesion which would not have otherwise been discovered.
With the rising incidence of $\mathrm{AC}$ in western countries, and the recognition of the association of GORD and Barrett's oesophagus, a new group of patients with early lesions discovered through screening or surveillance programs is emerging. These patients are generally found to have either Barrett's oesophagus or Barrett's dysplasia, and are then regularly followed with surveillance endoscopy. Several techniques have evolved for increasing sensitivity in finding early malignant or pre-malignant lesions. Chromoendoscopy involves endoscopic evaluation after staining with vital dyes such as Lugol's iodine, crystal violet, indigo carmine, and methylene blue. This technique has increased sensitivity and specificity to $89 \%$ and $86 \%$ respectively, for evaluation of Barrett's

Table 2: Risk factors associated with oesophageal cancer development (16)

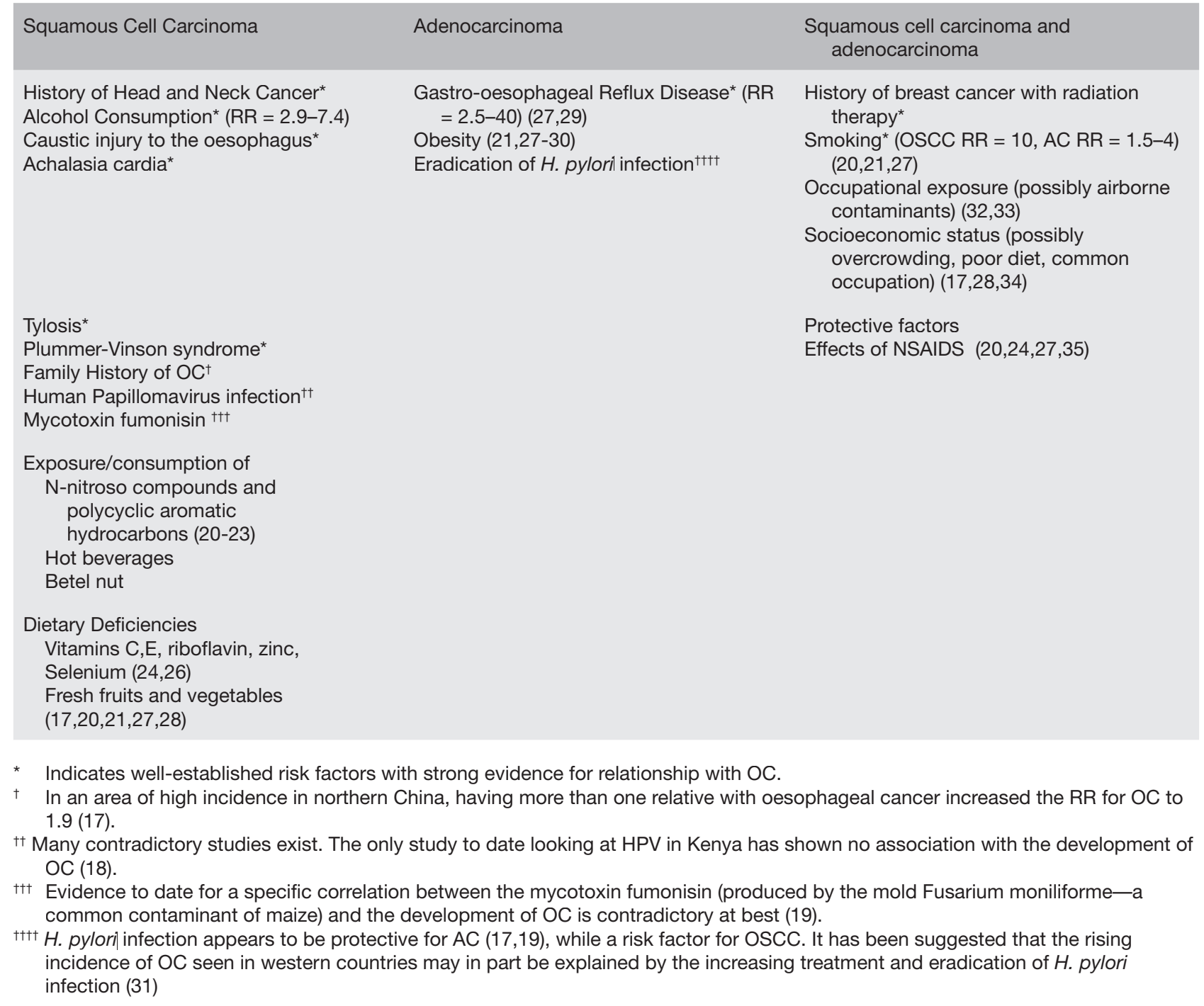


Table 3: Diagnostic/staging modalities for oesophageal cancer

$\begin{array}{ll}\text { Diagnosis } & \text { Use } \\ \text { Upper Gl endoscopy with biopsy } & \text { Initial modalities of choice } \\ \text { Barium swallow } & \\ \text { Primary tumour Assessment (T Stage) } & \\ \text { CT scan } & \text { Tumour size and presence of invasion into surrounding tissue } \\ \text { MRI } & \text { Slightly superior to CT in detecting vascular invasion } \\ \text { Endoscopic Ultrasound } & \text { Depth of invasion } \\ \text { Bronchoscopy } & \text { Possible airway invasion for tumour above level of carina } \\ \text { Regional assessment (N Stage) } & \\ \text { CT scan } & \text { Evaluating regional lymph nodes } \\ \text { Endoscopic ultrasound } & \\ \text { Distant metastases (M Stage) } & \\ \text { CT scan } & \\ \text { PET scan } & \text { Metastases detection especially liver and brain } \\ \text { Abdominal ultrasound } & \text { Sensitive detection of distant metastases } \\ \text { Fine needle aspiration } & \text { Helpful for abdominal spread } \\ \end{array}$

oesophagus (38). Light-induced fluorescence endoscopy (LIFE) and narrow band imaging (NBI) are two additional endoscopic techniques for improving sensitivity in finding early lesions. NBI, or virtual chromoendoscopy, in particular, appears to be very promising in this regard without the use of additional reagents (39). Oesophageal capsule endoscopy also is being used for Barrett's screening and surveillance programs. One clear disadvantage of this technique is the inability to obtain biopsy samples for histologic confirmation (40). Optical coherence tomography (OCT) is also a technique with some promise in distinguishing neoplasia within Barrett's mucosa (41). Use of these techniques in early diagnosis of OSCC has not achieved widespread success, but have shown promise in a number of studies in highrisk populations $(42,43)$.

Initial diagnostic evaluation tends to be either with barium swallow or upper endoscopy. The decision between these two modalities tends to be based upon regional availability of resources and referral patterns. Certainly, upper endoscopy is more reliable than contrast radiography, as small lesions can be missed on barium studies. Further, endoscopy allows for biopsy of suspicious lesions, permitting histologic confirmation of disease. In areas where OC is endemic, the clinical presentation of weight loss and dysphagia is nearly pathognomonic for OC (4). This finding is virtually reproduced in the author's institution, with the exception of cases of oesophageal candidiasis related to AIDS, which may cause severe dysphagia and weight loss as well. Additional diagnostic modalities with their appropriate uses in staging assessment are summarized in Table 3.

\section{Staging of oesophageal cancer}

The TNM staging system incorporated in the manual for Staging of Cancer of the American Joint Committee on Cancer (44) is the most widely used system for classifying OC. This scheme classifies OC into stage 0 through stage IV based on tumour depth/penetration, nodal status, and presence of metastases. Superficial cancers are defined as tumours limited to the mucosa or submucosa (45). Mucosal lesions can be further subdivided into m1-m3 lesions. Tumours that are confined within the basement membrane are classified as $\mathrm{ml}$ (described by some as "carcinoma-in-situ"). Lesions that invade into, but not through, the muscularis mucosa are considered $\mathrm{m} 3$. Lesions intermediate between these two would be considered $\mathrm{m} 2$. Submucosal lesions are similarly subdivided into sm1-sm3. The incidence of lymph node metastases in $\mathrm{ml}$, 
$\mathrm{m} 2$ and $\mathrm{m} 3$ lesions has been reported at $0 \%$, $3.3 \%$, and $12.2 \%$, with sml, sm2, and sm 3 lesions yielding a positive lymph node rate of $26.5 \%$, $35.8 \%$, and $45.9 \%$, respectively (46).

\section{Management options}

As described, historically patients have presented with OC only at late stages with advanced symptoms. In recent years, particularly in association with GORD and $\mathrm{BO}$, a number of patients are being found with either pre-malignant dysplasia, or OC at a very early stage. For purposes of this discussion, management options will be discussed in the categories of superficial lesions and premalignant dysplasia, invasive lesions with curative intent, and treatment with palliative intent.

\section{Superficial lesions/Pre-malignant dysplasia}

Multiple options exist for superficial malignant lesions of the oesophagus, including oesophagectomy, a variety of ablative therapies, and endoscopic mucosal resection (EMR). In most cases, ablative therapies are considered for pre-malignant dysplasia, but not for superficial carcinomas. Oesophagectomy has been advocated for high grade dysplasia (HGD) and early cancers, while EMR has been used for all grades of dysplasia and early carcinomas. Ablative therapies and EMR are generally considered for one of two reasons. First, given the relatively low risk of lymphatic spread with very early lesions, and the ability to completely remove or ablate the lesion endoscopically, the inherent morbidity and mortality associated with oesophagectomy may be avoided without compromising appropriate oncologic treatment principles and survival advantage. Second, individual patients often have associated comorbidity making treatment without the risk of oesophagectomy very attractive.

Currently, a number of different ablative therapies are available (47). The goal in all of these therapies is to achieve tissue destruction to various levels of the mucosa or submucosa.
After ablative therapy, patients are generally maintained on effective acid suppression therapy while allowing normal healing of the damaged tissue. Descriptions of a number of ablative techniques as well as their relative advantages and disadvantages are summarized in Table 4.

Endoscopic Mucosal Resection (EMR) is a technique whereby portions of the oesophageal mucosa and submucosa can be removed via the endoscope. Therefore, unlike the ablative techniques, tissue is retrieved during EMR for histologic examination. Several different specific techniques exist. However, all of them have the general principle of submucosal injection of saline (with or without epinephrine or dye) to delineate a submucosal plane and facilitate resection. The involved mucosa, and varying degrees of submucosa, are then resected using electrosurgical techniques.

Newer variations of EMR, such as endoscopic submucosal dissection, have allowed the resection of progressively larger and deeper lesions. These techniques have been frequently pioneered and further developed by Japanese endoscopists (53). Although EMR was initially considered only in cases of premalignant lesions, or very superficial malignant lesions (i.e. $\mathrm{ml}$ lesions), the indications are becoming broader, and some authors are now advocating use of EMR for $\mathrm{m} 3$ and even sm 1 lesions, provided they are less than $25 \mathrm{~mm}$ in diameter and have no evidence of lymphatic invasion (54). In appropriately selected patients, EMR can achieve complete local remission in more than $90 \%$ of cases of HGD and superficial cancers, although recurrence of malignancy may occur in approximately $25 \%$ of cases (55). Bleeding complications with EMR are more common $(17 \%)$, but few require specific intervention, and stricture formation occurs in $6 \%-23 \%$ of cases (55).

\section{Invasive lesions with curative intent}

While radiation therapy alone, or in combination with chemotherapy has been used in some cases with a small number of long term survivors, in general, surgical resection is the mainstay of 
Table 4: Ablative techniques for Barrett's oesophagus and dysplasia

\begin{tabular}{|c|c|c|c|}
\hline Technique & Description & Advantages & Disadvantages \\
\hline PDT (48) & $\begin{array}{l}\text { Systemic administration of a chemical } \\
\text { photosensitizer. Light is applied } \\
\text { endoscopically to the area generating } \\
\text { oxygen free radicals and toxic species } \\
\text { leading to tissue destruction }\end{array}$ & $\begin{array}{l}\text { High effectiveness in 54- } \\
87 \%\end{array}$ & $\begin{array}{l}\text { Complications of chest pain, } \\
\text { cutaneous toxicity (30\%), fever } \\
\text { (33\%), pleural effusions (33-75\%), } \\
\text { stricture (58\%) } \\
\text { High Cost }\end{array}$ \\
\hline MPEC (49) & $\begin{array}{l}\text { Utilizes thermal energy with an } \\
\text { electrical circuit between two or } \\
\text { more electrodes on a probe tip that is } \\
\text { passed through an endoscope }\end{array}$ & $\begin{array}{l}\text { Success rates of } 75 \% \\
\text { Low cost } \\
\text { Less serious complications }\end{array}$ & $\begin{array}{l}\text { Low success with long lesions } \\
\text { Complications of dysphagia, } \\
\text { odynophagia, chest pain } x 4 \text { days } \\
\text { in } 41 \%\end{array}$ \\
\hline $\begin{array}{l}\text { Laser } \\
\text { therapy } \\
(47)\end{array}$ & $\begin{array}{l}\text { A variety of different lasers. Utilizes } \\
\text { the heat of laser directed at the lesion } \\
\text { to destroy tissue }\end{array}$ & Less serious complications & $\begin{array}{l}\text { High cost } \\
\text { Subsquamous metaplasia (90\%) }\end{array}$ \\
\hline APC (50) & $\begin{array}{l}\text { Involves passing a monopolar electric } \\
\text { current through ionized argon gas } \\
\text { delivered via an endoscopic probe }\end{array}$ & $\begin{array}{l}\text { Less depth of injury } \\
\text { Effective resolution of BO } \\
(38-98.6 \%)\end{array}$ & $\begin{array}{l}\text { Serious complications including } \\
\text { stricture, bleeding, perforation, } \\
\text { and death occur in up to } 24 \% \\
\text { Subsquamous metaplasia (30\%) }\end{array}$ \\
\hline RFA (51) & $\begin{array}{l}\text { Balloon-based bipolar electrode } \\
\text { allows for circumferential destruction } \\
\text { of the mucosa, without direct injury to } \\
\text { the submucosa }\end{array}$ & $\begin{array}{l}\text { Elimination of non- } \\
\text { dysplastic BO }(70 \%)\end{array}$ & $\begin{array}{l}\text { Relatively new technique without } \\
\text { significant studies }\end{array}$ \\
\hline $\begin{array}{l}\text { Cryo- } \\
\text { ablation } \\
(47,52)\end{array}$ & $\begin{array}{l}\text { Involves the delivery of liquid nitrogen } \\
\text { via a low pressure spray to cause } \\
\text { tissue destruction through induced } \\
\text { apoptosis and cryonecrosis }\end{array}$ & $\begin{array}{l}\text { Ablation of BO/HGD }(82 \%) \\
\text { Lower cost } \\
\text { Less serious complications }\end{array}$ & Multiple treatments required \\
\hline
\end{tabular}

PDT = Photodynamic Therapy, HGD = High Grade Dysplasia, MPEC = Multipolar Electrocoagulation, APC = Argon Plasma Coagulation, RFA = Radiofrequency Ablation

therapy in cases where pre-operative evaluation indicates that cure is possible and the patient is fit for surgery. The areas of controversy include the type and "radicality" of resection, the extent of surgical lymphadenectomy, and the addition of adjuvant therapy.

\section{Type of Surgical Resection}

The three main types of surgical resection being performed today include the transthoracic oesophagectomy (TTO), transhiatal oesophagectomy (THO) and more recently the minimally invasive oesophagectomy (MIO). The TTO procedure can be performed via either a right or left thoracotomy, although the right-sided thoracic approach is certainly more common and accepted. The classic Ivor Lewis TTO begins with a laparotomy for gastric mobilization, followed by right thoracotomy and tumour mobilization and resection.
Gastrointestinal continuity is restored by an anastomosis between the gastric fundus and the proximal oesophagus in the apex of the right chest. The three-field approach is a variant of the TTO and begins with a right thoracotomy for tumour and oesophageal mobilization. The chest is then closed and a laparotomy and left cervical incision is performed. The oesophagus is divided in the neck and the specimen is removed via the abdomen, with the anastomosis placed in the left neck. The THO, or so-called blunt oesophagectomy, involves a laparotomy and left cervical incision only. The thorax is never opened, and the tumour and oesophagus are mobilized and resected via blunt, transhiatal dissection. The gastro-oesophageal anastomosis is created in the left cervical position. The MIO has only recently emerged as an option and is going through significant evolution. However, in general, this approach involves thoracoscopic mobilization of the tumour and oesophagus, 
followed by laparoscopic gastric mobilisation and transhiatal oesophagectomy, with a left neck incision and cervical anastomosis.

In general, oesophagectomy is a relatively morbidoperationwithhighratesofcomplications and mortality, compared with other surgical procedures. The most common complications include pulmonary and cardiac complications, anastomotic leak and stricture formation. The rates of these complications vary significantly between series, but overall complication rates are approximately $50 \%$, and are summarised in Table 5. In general, most series show a higher rate of anastomotic leak for cervical anastomoses compared with intra-thoracic anastomoses. However, this fact must be considered in light of the fact that the mortality for an intra-thoracic leak is much higher than that for a leak in the cervical position. It is largely for this reason that this author's personal practice is to place all oesophagogastric anastomoses in the neck.

\section{Table 5: Complications following oesophagectomy}

\begin{tabular}{|lc|}
\hline Complication & Incidence (\%) \\
\hline Pulmonary complications & $15-57$ \\
\hline Cardiac complications & $16-26$ \\
\hline Anastomotic stricture & $6-36$ \\
Anastomotic leak & $4-16$ \\
Vocal chord paralysis & $0-21$ \\
Wound infection & $8-10$ \\
Chylothorax & $1-10$ \\
Gastric necrosis & $1-4$ \\
\hline
\end{tabular}

Mortality related to oesophagectomy has been decreasing in recent years, but remains significant, with most series reporting mortality rates of $5 \%-10 \%$ for patients resected for cure (57). Most advanced, high-volume surgical centres are now aiming for surgical mortality to be less than $5 \%$. However, it is interesting to note that in the USA, a recent review of the Medicare database revealed a mortality rate that ranged from $8 \%$ in high-volume centers to
$23 \%$ in institutions in which the procedure was not commonly performed (58).

Significant controversy exists in the surgical literature regarding the best surgical approach to OC. On the one hand is the "radical" philosophy advocating radical, en-bloc resection of $\mathrm{OC}$, to include the primary tumour and the pericardium, thoracic duct, azygous vein, intercostal vessels, bilateral pleurae overlying the tumour, and a cuff of crura if the tumour is abutting. The associated two-field lymphadenectomy involves en-bloc resection of all nodal groups between the tracheal bifurcation superiorly and the celiac axis inferiorly (59). This approach was first proposed by Logan in 1963 (60), and further expanded upon by Skinner and colleagues in the early 1980's (61). On the other hand is the view that OC tends largely to be a systemic disease at the time of diagnosis, and thus surgical intervention should be considered primarily palliative. This view is championed by Orringer and other advocates of the transhiatal oesophagectomy (62). A considerable body of evidence exists in the literature to support either view. A relatively recent meta-analysis of a decade of studies comparing TTO with THO showed no difference in 5-year survival between the two approaches, but significantly higher morbidity and mortality with the TTO approach. One year later, the same authors published one of the few prospective, randomized studies comparing the two approaches, which included "radical" lymphadenectomy. This study showed no difference in mortality between TTO and $\mathrm{THO}$, a statistically higher rate of morbidity with TTO, and a non-significant trend toward improved survival in the TTO group (64). It is likely that this debate will continue indefinitely and that surgical technique will continue to be largely influenced by regional training and practice patterns. It is this author's opinion that the choice of the operation should be tailored to the individual patient characteristics, such that TTO should clearly be considered for upper and mid thoracic lesions, while THO is an option for distal lesions. 


\section{Extent of Surgical Lymphadenectomy}

The question of the appropriate extent of lymphadenectomy associated with oesophagectomy is related to, but separate from the question of surgical approach. While there are significant variations in definitions in today's literature, it is generally accepted that a "twofield" lymph node dissection involves resection of the nodes and peri-oesophageal tissue below the level of the carina and the lymph node stations around the celiac trunk. When superior mediastinal lymph node dissection is added to this, it is frequently referred to "extended or total two-field lymphadenectomy" (65). However, in Japanese literature, the addition of the superior mediastinal lymphadenectomy is often assumed. The term "three-field lymphadenectomy" implies the addition of bilateral cervical lymph node dissection. The rationale for this radical lymphadenectomy is based on the finding that up to one third of patients undergoing curative resection for $\mathrm{OC}$ will have occult cervical lymph node metastases (59). In relation to the primary tumour location, cervical node involvement is found in $60 \%$, $20 \%$, and $12.5 \%$ of upper, mid, and lower third tumours respectively (64). Once again, one can find ample evidence to support the view that a more extended lymphadenectomy improves survival (66), or that a more extended lymphadenectomy does not improve survival (62). One common argument against the evidence supporting improved survival in more extended lymphadenectomies is the observation of stage migration. This refers to the situation in which the additional dissection upstages a patient. Therefore, a patient who would have been staged at a lower stage (e.g. stage I or II) is upstaged to stage IV based on the cervical lymphadenectomy. By removing this patient from the early stage patients, it then improves observed survival in this group of patients. It would also appear that the additional dissection of the three-field lymphadenectomy does increase morbidity (67), although there are significant variations between surgical centers. Currently, three field lymphadenectomy is commonly performed in Japan, while few western centers perform this procedure with regularity. Again, it appears that this debate will continue and that practice patterns will largely be determined by training patterns and personal choice.

\section{Adjuvant Therapy}

A great deal of interest has been expressed in recent years regarding adjuvant therapy in the treatment of OC. Focus has shifted to pre-operative (so-called neoadjuvant) chemotherapy and combined chemoradiation therapy since radiotherapy alone has not proved to be effective (68). Post-operative chemoradiation therapy has also not shown promise (69). A number of randomized studies have compared neoadjuvant chemotherapy and surgery to surgery alone $(70,71)$. Of these studies, only the MRC trial (the largest of the trials) showed a statistically significant survival advantage with hazard ratio of 0.79 and $95 \%$ confidence interval of 0.67-0.93 (71). In a similar fashion, numerous randomized studies have compared neoadjuvant chemoradiation therapy and surgery and with surgery alone $(70,72)$. Of these studies, only two have shown significant survival advantages with a hazard ratios of 0.58 and $95 \%$ CI $0.38-0.88$ (72). In many of these studies, morbidity (up to $80 \%$ ) and mortality $(2 \%-8 \%)$ associated with adjuvant treatment has been significant (73). A number of different meta-analyses have been performed attempting to combine the results of these relatively small randomized series $(74,75)$. In general, these meta-analyses have failed to show any significant improvement in survival with adjuvant treatment. However, one of the most recent studies has demonstrated significant improvement in survival for both neoadjuvant chemotherapy and chemoradiation therapy. This meta-analysis included several nonpublished studies which had not been included in previous analyses $(76,77)$. One of these studies (77) showed a marked improvement in survival favoring neoadjuvant chemoradiation therapy and surgery over surgery alone. This metaanalysis reported a hazard ratio for all-cause mortality with neoadjuvant chemoradiation therapy and surgery versus surgery alone of 
0.81 (95\% CI 0.70-0.93; $\mathrm{p}=0.002)$, corresponding to a $13 \%$ absolute difference in survival at two years. This result differed slightly for OSCC with hazard ratio of 0.84 (95\% CI 0.71-0.99; $\mathrm{p}=0.04)$, than for AC with a hazard ratio of 0.75 (95\% CI 0.59-0.95; p = 0.02). The hazard ratio for neoadjuvant chemotherapy was 0.90 (95\% CI 0.81-1.00; $\mathrm{p}=0.05)$, which indicates a two-year absolute survival benefit of $7 \%$. This benefit was significant for AC with a hazard ratio of 0.78 (95\% CI $0.64-0.95 ; \mathrm{p}=0.014)$, was not statistically significant for OSCC (75). This result has led some to consider neoadjuvant treatment as the standard of care for OC (78). While it seems clear that patients who achieve a complete pathologic response to neoadjuvant therapy appear to have improved survival (79) and that neoadjuvant therapy may downstage patients and improve rates of complete surgical resection (80), it is not entirely clear what group of patients will ultimately benefit from neoadjuvant therapy. A recent study combined a meta-analysis of survival benefit with decision analysis evaluating relative risk for mortality and quality of life. This study demonstrated a very small increase in quality adjusted life years for neoadjuvant chemoradiation therapy and surgery compared with surgery alone, and concluded that surgery alone may be the preferred treatment in advanced OC (74). On a global basis, it appears that neoadjuvant therapy will likely become standard of care in resource rich areas (such as westernized countries where $\mathrm{AC}$ is more common), while surgical resection alone will remain the cornerstone of treatment for much of the world where OSCC predominates.

\section{Treatment with palliative intent}

Recognizing that less than one third of patients with OC are candidates for operative treatment with curative intent, it is obvious that palliation will be the goal in the majority of patients with OC (81). Palliation is defined as the easing of symptoms without curing the underlying disease. Since the majority of the serious symptoms related to incurable OC are related to oesophageal obstruction (i.e. dysphagia and weight loss), the goals of palliation are generally directed toward overcoming oesophageal obstruction and improving dysphagia. Chest and abdominal pain are generally managed with narcotic and non-narcotic pain medications, while bleeding is particularly difficult to palliate without resection.

Virtually all of the ablative techniques previously described have been used for palliation of advanced OC (82-86). Additionally, chemotherapy, radiation therapy, brachytherapy, direct ethanol injection, endoscopic intubation or stenting, and palliative surgery have all been utilized in the treatment of OC not amenable to resection (87-92). The simple fact that so many options exist would certainly seem to imply that there is no clear consensus on the most effective palliative technique. However, several observations should be made. When one talks of palliative surgical treatment of oesophageal cancer, the most common situation is that of discovering that a tumour is unresectable or discovering the presence of metastases at the time of attempted surgical resection. The literature is in fact nearly absent of studies looking specifically at surgical palliation which was planned pre-operatively, with only one clear study in this area. This is due to the inherent difficulty in surgically treating $O C$ with anything less than resection. Partial resection or debulking procedures are nearly always fraught with complications and mortality. It is this author's opinion that during surgical exploration for intended resection, if the surgeon does not feel reasonably sure that at minimum an $\mathrm{R} 1$ resection can be carried out (in which all gross disease is removed)-and preferably an $\mathrm{RO}$ resection (in which microscopic margins are negative), then no resection should be performed, and an alternate form of palliation should be pursued. Surgical bypass is difficult to perform due to the anatomic position of the oesophagus, and carries a very high rate of morbidity and mortality.

While chemotherapy alone has not been shown generally to provide significant palliation, chemoradiation therapy, or radiation therapy alone seems to provide temporary improvement in swallowing in appropriately selected patients. Radiotherapy has been utilized particularly in proximal oesophageal lesions, where other palliative treatments are 
more difficult. All of the ablative techniques used for palliation have met with some success. However, common to all of these techniques. is the need for re intervention, with dysphagia often recurring as soon as one month after treatment (94). In patients with non-curable OC, survival is measured in weeks and months, and so providing palliation with as few treatment sessions as possible is certainly preferable.

Endoscopic intubation or stenting has become more common in recent years, and is now the most common technique utilized for palliative treatment of advanced OC (91). In earlier years, stenting was performed with a variety of plastic, metal, or wooden prostheses. A nice review of the history of stenting is provided by Mitton and Ackroyd (91). Common to all of these prostheses was the difficulty in insertion often requiring general anesthesia and laparotomy. Additionally, these fairly rigid, smooth prostheses had a very significant rate of migration (95). The introduction of self-expanding metal stents (SEMS) in 1983 heralded the beginning of a new era in the use of stents (96). Since that time, the use of SEMS has virtually replaced rigid endoprostheses in much of the world. The procedure of inserting SEMS is generally performed with conscious sedation. Although fluoroscopy may be helpful in placement, it is certainly not required (97). Currently, SEMS with a plastic coating are most commonly used to reduce the incidence of tumour ingrowth through the interstices of the stent. Stent placement can be performed as an outpatient procedure, and combined with dilation, provides immediate improvement in dysphagia. Early or immediate complications are generally related to dilation or misplacement and include perforation and airway compromise. Whereas oesophageal perforation is generally considered a surgical emergency, perforation of an unresectable malignancy can usually be treated effectively with placement of a coated SEMS (98). Later complications of SEMS include chest pain, stent migration, stent occlusion, and bleeding. Morbidity and mortality is clearly lower with SEMS than with rigid prostheses (99). While some have reported complications as high as $16 \%-45 \%$ and mortality rates as high as 9\%, (99). Others have reported 5\% late complications and $0 \%$ mortality with very good reduction in dysphagia until death (100).

\section{Outcome/survival}

On a global basis, overall 5-year survival of OC is significantly less than $10 \%(29,101)$. In the USA, the American Cancer Society estimated that there would be 11,260 new cases of OC in men, and 3,290 cases in women. In the same year they estimated that 10,730 men and 3,040 women would die of the disease, indicating very high case fatality (7). In the USA, 5-year survival estimates for OSCC has improved from $4.6 \%$ in $1974-1979$ to $12.3 \%$ in $1992-1997$, while AC has seen an improvement from $5.3 \%$ to $13.7 \%$ for the same time period (102). In patients undergoing potentially curative resection, overall 5-year disease-free, all-stage survival is approximately $30 \%$ with median survival of 21 months $(64,103)$. This is, of course, highly dependent upon the stage of the disease at the time of diagnosis and treatment, and is summarised in Table 6.

Table 6: Survival following oesophagectomy for oesophageal cancer

$\begin{array}{ccc}\text { Stage } & \text { 5-year survival (\%) } & \text { Median Survival } \\ \text { O } & 68-100 & \text { NR }^{*} \\ \text { I } & 42-78 & 44-78 \text { months } \\ \text { II } & 26-72 & 23-59 \text { months } \\ \text { III } & 15-39 & 14-53 \text { months } \\ \text { IV } & 0-27 & 7-20 \text { months }\end{array}$

${ }^{*}$ NR: Not Reported

Source: $59,103,106$ 
The most important prognostic factors for patients undergoing surgical resection for OC appears to be the ability to carry out an $\mathrm{RO}$ resection, and the presence (and absolute number) or absence of involved lymph nodes. There are, however, a number of other factors which have prognostic significance, and these are summarised in Table 7.

\section{Table 7: Prognostic factors following oesophagectomy for oesophageal cancer}

Weight loss before operation
Duration of symptoms
Tumor location (proximal tumors indicate worse
prognosis)
Radicality of resection (i.e. RO vs. R1 vs. R2)
Pathologic Stage
Presence and absolute number of involved lymph
nodes
Grade of differentiation
Neural invasion
Vascular invasion

Source: $103,104,107$

\section{Oesophageal cancer in Kenya}

Relatively few published reports exist regarding the situation of OC in Kenya The earliest published report is from a colonial officer in 1935 who reported several cases of OC (108). Nevill then reported 79 cases of OC from what is now Kenyatta National Hospital in Nairobi (109). Ahmed and Cook published several case-series from 1966 to 1971, with OC accounting for $25 \%-30 \%$ of all cancers $(110,111)$. These reports indicated that in certain regions of central and west Kenya, OC ranked as the first or second most common cancer. In 1978, Gatei and colleagues reported OC as the fifth most common cancer nationwide, accounting for $5.4 \%$ of solid malignancies (112). This study reported an overall incidence for the country of 0.67 per 100,000 per year. This would imply that Kenya is an area of extremely low incidence of OC. Further, they reported the incidence of OC among the Kalenjin tribes at 0.2 per 100,000 per year.Unfortunately, theserateswere based solely on cases that were histologically confirmed at the central pathology laboratory in Nairobi and reported to the Kenya Cancer Registry. Since most of the hospitals did not have the resources to perform histological studies, these numbers clearly grossly underestimated the actual incidence. White et al reported their experience with OC in southwestern Rift Valley Province from 1989 to 1998 (5). In our series, OC was the most common malignancy for both men and women, accounting for $19 \%$ of all malignancies. The male to female ratio was 1.4 to 1 with OSCC accounting for $90 \%$ of cases. The median age at diagnosis was 54 for men and 56 for women. There was a significant proportion of patients presenting at a young age, with $11 \%$ of cases aged 30 years or less, with the youngest patient presenting at age 14 . This is quite a striking finding which has not been reported in any other place world-wide. Even in areas of extremely high incidence of OC, such as Linxian, China, cancer cases in people aged 30 years or less are extremely rare, with a proportion of less than $1 \%$ (113). In western countries, such as the USA, this proportion is even lower at $0.18 \%(10)$.

More recently, Wakhisi et al. described the experience with $\mathrm{OC}$ at Moi Teaching and Referral Hospital in Eldoret (4). They described $\mathrm{OC}$ as the most common cancer in men, and the third most common malignancy in women. In this series, OC accounted for $13.8 \%$ of all malignancies, with OSCC accounting for $90 \%$ of cases. The male to female ratio was 1.5 to 1 . The mean age at diagnosis was 59 years, with $10 \%$ of cases less than 40 years old. The youngest patient in the series was 20 years old. This series attempted to describe an incidence rate of more than 30 per 100,000 per year for men, with approximately half of that for women. However, it is very unclear how this incidence was calculated. Recognizing the inherent difficulty in establishing valid incidence rates (i.e. assuring that all cases are reported, and knowing the number of the total population at risk), it is probably wiser not to report incidence rates. Elsewhere in Kenya, the Nairobi Cancer Registry reported cancer cases registered during 2000-2002. They found that OC was the most common single site cancer among men at $10 \%$ of all malignancies, while it was third most 
common (behind breast and uterus/cervix) accounting for $4.4 \%$ of all malignancies (114).

It is clear that OC is one of the most common cancers in Kenya. Whether or not specific geographic sites of very high incidence within the country exist is not clear at this point. What is clear to anyone who sees OC patients in Kenya with regularity is that the vast majority of patients are presenting at a very late stage. For most patients, surgical resection for cure is not an option due to either very late stage disease, very poor overall condition of the patient, or both. Very little has been done to identify patients at early stages of the disease, although at least one study has been reported looking at the feasibility of a screening program for OC in Kenya (115). At Tenwek Hospital, patients with OC undergo upper GI endoscopy, chest radiograph, abdominal ultrasound and HIV testing. Patients with upper oesophageal lesions also undergo bronchoscopy. The exclusion criteria for surgical resection are summarized in Table 8 . Those found to have no contraindications for surgical resection (generally approximately $10 \%$ of all OC patients seen) are offered surgery with curative intent. The remaining $90 \%$ of patients are usually offered stenting with self-expanding metal stents. In general, it is difficult to arrange either adjuvant or primary chemotherapy or radiation therapy for the majority of OC patients in Kenya. Therefore, either surgical resection alone or stenting alone are the treatments most often available for patients with OC.

A great deal of work remains to be done regarding OC in Kenya. These projects include clarifying epidemiologic trends and patterns, examining potential risk factors and etiologies, further defining the role of screening programs and early intervention, clarifying the role of surgical and adjuvant treatment, and improving the availability of palliative care for the many cases of advanced OC which will surely continue to present to many health care workers throughout the country. There is a tendency to become somewhat fatalistic when dealing with this disease in our context. This has led some to question whether there is any hope at all for making progress regarding OC (12). However, with appropriate work and diligence, there is tremendous potential to make significant contributions toward the understanding of this disease, and to provide preventative, curative, and palliative care to a very large number of people in need.

Table 8: Contraindications to oesophagectomy at
Tenwek Hospital

\begin{tabular}{ll} 
Absolute & Contraindications \\
\hline $\begin{array}{l}\text { Distant Metastases } \\
\begin{array}{l}\text { Tracheo-oesophageal } \\
\text { fistula }\end{array}\end{array}$ & $\begin{array}{c}\text { Age } 80 \text { years } \\
\text { Extreme cachexia/ } \\
\text { malnutrition }\end{array}$ \\
$\begin{array}{l}\text { Phrenic or recurrent } \\
\text { laryngeal nerve palsy }\end{array}$ & Poor exercise tolerance \\
HIV positivity & \\
Relative Contraindications &
\end{tabular}

\section{References}

1. Parkin D.M., Bray F., Ferlay J., et al. Global cancer statistics, 2002. CA Cancer J. Clin. 2005; 55: 74-108.

2. Munoz N. and Day N. Esophageal Cancer. In: SchottenfeldD.,FraumeniJ., eds. Cancerepidemiology and prevention. New York: Oxford University Press, 1996; 681-706.

3. Ahmed N. and Cook P. The incidence of cancer of the oesophagus in West Kenya. Brit. J. Cancer. 1969; 23: 302-312.

4. Wakhisi J., Patel K., Buziba N., et al. Esophageal cancer in north rift valley of western Kenya. African Health Sciences. 2005; 5(2): 157-163.

5. White R.E., Abnet C., Mungatana C., et al.oesophageal cancer: a common malignancy in young people of Bomet District, Kenya. Lancet. 2002; 360: 462-463.

6. Gallo A. and Cha C. Updates on esophageal and gastric cancers. World J. Gastroenterol. 2006; 12: 3237-3242.

7. Holmes R.S. and Vaughan T.L. Epidemiology and pathogenesis of esophageal cancer. Semin. Radiat. Oncol. 2007; 17(1): 2-9. Review.

8. El-Serag H.B., Mason A.C., Peterson N., et al. Epidemiological differences between adenocarcinoma of the oesophagus and adenocarcinoma of the gastric cardia in the USA. Gut. 2002; 50: 368-372.

9. Siewert J.R. and Ott K. Are squamous and adenocarcinomas of the esophagus the same disease? Semin. Radiat. Oncol. 2007; 17(1): 38-44. Review.

10. Ries L.A.G., Eisner M.P., Kosary C.L., et al. (eds). 
SEER cancer statistics review, 1975-2001. Bethesda, MD: National Cancer Institute; 2004. Available at: http://seer.cancer.gov/csr/1975_2001/.

11. Sant M., Aareleid T., Berrino F., et al. EURO-CARE Working Group. EUROCARE-3: survival of cancer patients diagnosed 1990-94-results and commentary. Ann. Oncol. 2003; 14: v61-v118.

12. Walker A.R., Adam F., Walker J., et al. Cancer of the oesophagus in Africans in sub-Saharan Africa: any hopes for its control? Eur. J. Cancer Prev. 2002 Oct; 11(5): 413-418. Review.

13. White R.E., Kasepoi Z., Harewood G.C., et al. Experience with 1,345 Esophageal Cancer Patients Seen At a Single Mission Hospital in Western Kenya. Gastrointestinal Endoscopy. 2006; 63(5): AB124.

14. Lerut T., De L.P., Coosemans W., et al. Surgical strategies in esophageal carcinoma with emphasis on radical lymphadenectomy. Ann. Surg. 1992; 216: 583-590.

15. Holscher A.H., Bollschweiler E., Schneider P.M., et al. Prognosis of early esophageal cancer. Comparison between adeno- and squamous cell carcinoma. Cancer. 1995; 76: 178-186.

16. Enzinger P.C. and Mayer R.J. Esophageal Cancer. N. Engl. J. Med. 2003; 349: 2241-2252. Review.

17. Tran G.D., Sun X.D., Abnet C.C., et al. Prospective study of risk factors for esophageal and gastric cancers in the Linxian general population trial cohort in China. Int. J. Cancer. 2005; 113: 456-463.

18. White R.E., Mungatana C., Mutuma G., et al. Absence of human papillomavirus in esophageal carcinomas from southwestern Kenya. Dis. Esophagus. 2005; 18: 28-30.

19. Chu K.F.S. and Li G.Y. Simultaneous occurrence of fumonisin B1 and other mycotoxins in mouldy corn from the People's Republic of China in regions with high incidence of esophageal cancer. Appl. Environ. Microbiol. 1994; 60: 847-52.

20. Crew K.D. and Neugut A.I. Epidemiology of upper gastrointestinal malignancies. Semin. Oncol. 2004; 31: 450-464.

21. Blot W.J. and McLaughlin J.K. The changing epidemiology of esophageal cancer. Semin. Oncol. 1999; 26: 2-8.

22. Gammon M.D., Schoenberg J.B., Ahsan H., et al. Tobacco, alcohol, and socioeconomic status and adenocarcinomas of the esophagus and gastric cardia. J. Natl. Cancer Inst. 1997; 89: 1277-1284.

23. Thun M.J., Peto R., Lopez A.D., et al. Alcohol consumption and mortality among middle-aged and elderly U.S. adults. N. Engl. J. Med. 1997; 337: 1705-
1714.

24. Limburg P.J., Wei W., Ahnen D.J., et al. Randomized, placebo-controlled, esophageal squamous cell cancer chemoprevention trial of selenomethionine and celecoxib. Gastroenterol. 2005; 129: 863-873.

25. Li J.Y., Taylor P.R., Li B., et al. Nutrition intervention trials in Linxian, China: supplementation with specific vitamin/mineral combinations, cancer incidence, and disease-specific mortality in the general population. J. Natl. Cancer Inst. 1993; 85: 1492-1498.

26. Blot W.J., Li J.Y., Taylor P.R., et al. Nutrition intervention trials in Linxian, China: supplementation with' specific vitamin/mineral combinations, cancer incidence, and disease-specific mortality in the general population. J. Natl. Cancer Inst. 1993; 85: 1483-1492.

27. Pera M., Manterola C., Vidal O., et al. Epidemiology of esophageal adenocarcinoma. J. Surg. Oncol. 2005; 92: 151-159.

28. Brown L.M. and Devesa S.S. Epidemiologic trends in esophageal and gastric cancer in the United States. Surg. Oncol. Clin. N. Amer. 2002; 11: 235-256.

29. Lagergren J. Adenocarcinoma of oesophagus: What exactly is the size of the problem and who is at risk? Gut. 2005; 54: 1-5 (suppl 1).

30. Chow W.H., Blot W.J. and Vaughan T. Body mass index and risk of adenocarcinomas of the esophagus and gastric cardia. J. Natl. Cancer Inst. 1998; 90: 150-155.

31. Ye W., Held M., Lagergren J., et al. Helicobacter pylori infection and gastric atrophy: Risk of adenocarcinoma and squamous-cell carcinoma of the esophagus and adenocarcinoma of the gastric cardia. J. Natl. Cancer Inst. 2004; 96: 388-396.

32. Jansson C., Plato N., Johansson A.L., et al. Airborne occupational exposures and risk of oesophageal and cardia adenocarcinoma. Occup. Environ. Med. 2006; 63: 107-112.

33. Engel L.S., Vaughan T.L., Gammon M.D., et al. Occupation and risk of esophageal and gastric cardia adenocarcinoma. Amer. J. Int. Med. 2002; 42: 11-22.

34. Jansson C., Johansson A.L., Nyren O., et al. Socioeconomic factors and risk of esophageal adenocarcinoma: A nationwide Swedish case-control study. Cancer Epidemiol. Biomarkers Prev. 2005; 14: 1754-1761.

35. Corley D.A., Kerlikowske K., Verma R., et al. Protective association of aspirin/NSAIDs and esophageal cancer: A systematic review and metaanalysis. Gastroenterol. 2003; 124: 47-56.

36. Sweet R.H. Results of radical surgical extirpation in treatment of carcinoma of the esophagus and cardia: 
With 5-year survival statistics. Surg. Gynecol. Obstet. 1952; 94: 46.

37. Yu Y., Taylor P.R., Li J.Y., et al. Retrospective cohort study of risk-factors for esophageal cancer in Linxian, People's Republic of China. Cancer Causes Control. 1993; 4(3): 195-202.

38. Amano Y., Kushiyama Y., Ishihara S., et al. Crystal violet chromoendoscopy with mucosal pit pattern diagnosis is useful for surveillance of short-segment Barrett's esophagus. Amer. J. Gastroenterol. 2005; 100: 21-26.

39. Kara M.A., Peters F.P., Rosmolen W.D., et al. Highresolution endoscopy plus chromoendoscopy or narrow-band imaging in Barrett's esophagus: a prospective randomized crossover study. Endoscopy. 2005; 37: 929-936.

40. Ramirez F.C., Shaukat M.S., Young M.A., et al. Feasibility and safety of string, wireless capsule endoscopy in the diagnosis of Barrett's esophagus. Gastrointest Endosc. 2005; 61: 741-745.

41. Isenberg G., Sivak M.V., Chak A., et al. Accuracy of endoscopic optical coherence tomography in the detection of dysplasia in Barrett's esophagus: a prospective, double-blinded study. Gastrointest Endosc. 2005; 62: 825-831.

42. Dawsey S.M., Fleischer D.E., Wang G.Q., et al. Mucosal iodine staining improves endoscopic visualization of squamous dysplasia and squamous cell carcinoma of the esophagus in Linxian, China. Cancer. 1998; 83: 220-231.

43. Wang G.Q., Abnet C.C., Shen Q., et al. Histologic precursors of esophageal squamous cell carcinoma: results from a 13-year prospective follow-up study in a high risk population. Gut. 2005; 54: 187-192.

44. AJCC Cancer staging. $6^{\text {th }}$ edn. Springer-Verlag; New York. 2002.

45. Japanese Society for Esophageal Diseases. Guide Lines for the Clinical and Pathologic Studies on Carcinoma of the Esophagus. 6th edn. Tokyo: Kanehara \& Co. Ltd, 1984 (in Japanese)

46. Kodama M. and Kakegawa T. Treatment of superficial cancer of the esophagus: a summary of responses to a questionnaire on superficial cancer of the esophagus in Japan. Surg. 1998; 123(4): 432-439.

47. Johnston M.H. Technology Insight: ablative techniques for Barrett's esophagus-current and emerging trends. Gastroenterol. Hepatol. 2005; 2(7): 323-330.

48. Photodynamic therapy for gastrointestinal disease. Gastrointest. Endosc. 2006; 63(7): 927-32.

49. Kovacs B.J., et al. Successful reversal of Barrett's esophagus with multipolar electrocoagulation despite inadequate acid suppression. Gastrointest. Endosc. 1999; 49: 547-553.

50. Madisch A., et al. Long-term follow-up after complete ablation of Barrett's esophagus with argon plasma coagulation. World J. Gastroenterol. 2005; 11: 11821186.

51. Sharma V., Wang K., Overholt B., et al. Balloon-based, circumferential, endoscopic radiofrequency ablation of Barrett's esophagus: 1-year follow-up of 100 patients. Gastrointest. Endosc. 2007; 65(2): 185-195.

52. Cash B.D., Johnston L.R. and Johnston M.H. Cryospray ablation (CSA) in the palliative treatment of squamous cell carcinoma of the esophagus. World J. Surg. Oncol. 2007; 5: 34.

53. Saetikno R., Kaltenbach T., Yeh R., et al. Endoscopic mucosal resection for early cancers of the upper gastrointestinal tract. J. Clin. Oncol. 2005; 23: 44904498.

54. Higuchi K., Tanabe S., Koizumi W., et al. Expanded indications for EMR in superficial esophageal carcinoma. Endoscopy. 2007; 39: 36-40.

55. Ciocirlan M., Lapalus M.G., Hervieu V., et al. EMR for squamous premalignant and early malignant lesions of the esophagus. Endoscopy. 2007; 39: 24-29.

56. Gu X.Z. Radiation therapy for carcinoma of the esophagus. In Huang G.J., Wu Y.K. (eds): Carcinoma of the Esophagus and Gastric Cardia. Berlin: Springer, 1984.

57. Mathisen D.J., Grillo H.C., Wilkins E.W., et al. Transthoracic esophagectomy: a safe approach to carcinoma of the esophagus. Ann. Thorac. Surg. 1988; 45: 137-145.

58. Birkmeyer J.D., Siewers A.E., Finlayson E.V., et al. Hospital and surgical mortality in the United States. N. Engl. J. Med. 2002; 346: 1128-1137.

59. Altkori N. En-bloc esophagectomy the three-field dissection. Surg. Clin. N. Amer. 2005; 85: 611-619.

60. Logan A. The surgical treatment of carcinoma of the esophagus and cardia. J. Thorac. Cardiovasc. Surg. 1963; 46: 150-161.

61. Skinner D.B., Little A.G., Ferguson M.K., et al. Selection of operation for esophageal cancer based on staging. Ann. Surg. 1986; 204(4): 391-401.

62. Orringer M.B., Marshall B. and Iannettoni M.D. Transhiatal esophagectomy: clinical experience and refinements. Ann. Surg. 1999; 230(3): 392-400.

63. Hulscher J.B.F., Tijssen J.G.P., Obertop H., et al. Transthoracic versus transhiatal resection for carcinoma of the esophagus: a metaanalysis. Ann. Thorac. Surg. 2001; 72: 306-313. 
64. Hulscher J.B.F., van Sandick J.W., de Boer A.G.E.M., et al. Extended transthoracic resection compared with limited transhiatal resection for adenocarcinoma of the esophagus. N. Engl. J. Med. 2002; 347: 1662-69.

65. Law S. and Wong J. Lymph node dissection in surgical treatment of esophageal neoplasms. Surg. Oncol. Clin. N. Amer. 2007; 16: 115-131.

66. Stein H. and Siewart J. Improved prognosis of resected esophageal cancer. World J. Surg. 2004; 28: 520-525.

67. Baba M., Aikou T., Natsugoe S., et al. Quality of life following esophagectomy with three-field lymphadenectomy for carcinoma, focusing on its relationship to vocal cord palsy. Dis. Esophagus. 1998; 11(1): 28-34.

68. Cooper J., Guo M., Herskovic A., et al. Chemoradiotherapy of locally advanced esophageal cancer: Long-term follow-up of a prospective randomized trial (RTOG 85-01). J. Amer. Med. Assoc. 1999; 281: 1623-1627.

69. Macdonald J.S., Smalley S.R., Benedetti J., et al. Chemoradiotherapy after surgery compared with surgery alone for adenocarcinoma of the stomach or gastroesophageal junction. N. Engl. J. Med. 2001; 345: 725-730.

70. Nygaard K., Hagen S., Hansen H., et al. Preoperative radiotherapy prolongs survival in operableesophageal carcinoma: a randomized multicenter study of preoperative radiotherapy and chemotherapy. The second Scandinavian trial in esophageal cancer. World J. Surg. 1992; 16: 1104-1110 .

71. Medical Research Council Oesophageal Cancer Working Group. Surgical resection with or without preoperative chemotherapy in oesophageal cancer: a randomized controlled trial. Lancet. 2002; 359: 1727-1734.

72. Walsh T., Noonan N., Hollywood D., et al. A comparison of multimodal therapy and surgery for esophageal adenocarcinoma. N. Engl. J. Med. 1996; 335: 462-467.

73. Heath E.I., Burtness B.A., Heitmiller R.F., et al. Phase II evaluation of preoperative chemoradiation and postoperative adjuvant chemotherapy for squamous cell and adenocarcinoma of the esophagus. J. Clin. Oncol. 2000; 18: 868-876.

74. Graham A.J., Shrive F.M., Ghali W.A., et al. Defining. the optimal treatment of locally advanced esophageal cancer: A systematic review and decision Analysis. Ann. Thorac. Surg. 2007; 83: 1257-1264.

75. Gebski V., Burmeister B., Smithers M.B., et al. Survival benefits from neoadjuvant chemoradiotherapy or chemotherapy in oesophageal carcinoma: a metaanalysis. Lancet Oncol 2007; 8: 226-34.

76. Walsh T. The role of multimodality therapy in improving survival: a prospective randomized trial. In: Predicting, defining and improving outcomes for oesophageal carcinoma (MD thesis). Dublin: Trinity College, University of Dublin 1995: 124-150.

77. Tepper J., Krasna M., Niedzwiecki D., et al. Superiority of trimodality therapy to surgery alone in esophageal cancer: results of CALGB 9781 (abstract). J. Clin. Oncol. 2006; 24(suppl 185): 4012.

78. Greil R. and Stein H.J. Is it time to consider neoadjuvant treatment as the standard of care in oesophageal cancer? Lancet Oncol. 2007; 8: 189-190.

79. Thomas C.R., Jr. Current and ongoing progress in therapy for resectable esophageal cancer. Dis. Esophagus. 2005; 18: 211-214.

80. Korst R.J., Kansler A.L., Port J.L., et al. Downstaging of $\mathrm{T}$ or $\mathrm{N}$ predicts long-term survival after preoperative chemotherapy and radical resection for esophageal carcinoma. Ann. Thorac. Surg. 2006; 82: 480-485.

81. Law S. and Wong J. Current management of esophag. eal cancer. J. Gastrointest. Surg. 2005; 9: 291-310.

82. Reed C.E. Comparison of different treatments for unresectable esophageal cancer. World J. Surg. 1995; 19: 828-835.

83. Moghissi K., Dixon K., Thorpe J.A., et al. The role of photodynamic therapy in inoperable esophageal cancer. Eur. J. Cardiothorac. Surg. 2000; 17: 95-100.

84. Loizou L.A., Grigg D., Atkinson M., et al. A prospective comparison of laser therapy and intubation in endoscopic palliation for malignant dysphagia. Gastroenterol. 1991; 100: 1303-1310.

85. Robertson G.S., Thomas M., Jamieson J., et al. Palliation of oesophageal carcinoma using the argon beam coagulator. Brit. J. Surg. 1996; 83: 1769-1771.

86. Johnston J.H., Fleischer D., Petrini J., et al. Palliative bipolar electrocoagulation therapy of obstructing esophageal cancer. Gastrointext Endosc. 1987; 33: 349-353.

87. Brown S.G. Palliation of malignant dysphagia: surgery, radiotherapy, laser, intubation alone or in combination? Gut. 1991; 32: 841-844.

88. Monga S.P., Wadleigh R., Sharma A., et al. Intratumoral therapy of cisplatin/epinephrine injectable gel for palliation in patients with obstructive esophageal cancer. Amer. J. Clin. Oncol. 2000; 23: 386-392.

89. Payne-James J.J., Spiller R.C., Misiewicz J.J., et al. Use of ethanol-induced tumor necrosis to palliate 
dysphagia in patients with esophagogastric cancer. Gastrointest. Endosc. 1990; 36: 418-419.

90. Christie N.A., Patel A.N. and Landreneau R.J. Esophageal palliation-photodynamic therapy/ stents/brachytherapy. Surg. Clin. N. Amer. 2005; 85: 569-582.

91. Mitton D. and Ackroyd R. Oesophageal stenting. Scandinavian J. Gastroenterol. 2005; 40: 1-14.

92. Sordeide J.A., Gronbech J.E. and Mjaland O. Effects and outcomes after palliative surgical treatment of malignant dysphagia. Scandinavian J. Gastroenterol. 2006; 41: 376-381. Review.

93. Segalin A., Little A.G., Ruol A., et al. Surgical and endoscopic palliation of esophageal carcinoma. Ann. Thorac. Surg. 1989; 48: 267-271.

94. Lightdale C.J., Heier S.K., Marcon N.E., et al. Photodynamic therapy with porfimer sodium versus thermal ablation therapy with Nd:YAG laser for palliation of esophageal cancer: a multicenter randomized trial. Gastroint. Endosc. 1995; 42: 507-512.

95. Davies N., Thomas H.G. and Eyre-Brook I.A. Palliation of dysphagia from inoperable oesophageal carcinoma using Atkinson tubes or self-expanding metal stents. Ann. R. Coll. Surg. Engl. 1998; 80: 394-397.

96. Frimberger E. Expanding spiral: a new type of prosthesis for the palliative treatment of malignant esophageal stenoses. Endoscopy 1983; 15(Suppl 1): 213-214.

97. White R.E., Mungatana C. and Topazian M. Esophageal stent placement without fluoroscopy. Gastrointest Endosc. 2001; 53(3): 348-351.

98. White R.E., Mungatana C. and Topazian M. Expandable stents for iatrogenic perforation of esophageal malignancies. J. Gastrointest Surg. 2003; 7(6): 715-719.

99. Knyrim K., Wagner H.J., Bethge N., et al. A controlled trial of an expansile metal stent for palliation of esophageal obstruction due to inoperable cancer. $N$. Engl. J. Med. 1993; 28: 1302-1307.

100. White R.E., Mungatana C., Harewood G.C., et al. Selfexpanding metal stents as sole treatment for advanced esophageal cancer. Dis. Esophagus. 2004; 17 (S1): A53.

101. Bosset J.F., Lorchel F., Mantion G., et al. Radiation and chemoradiation therapy for esophageal adenocarcinoma. J. Surg. Oncol. 2005; 92: 239-245.

102. Siewert J.R., Stein H.J., Feith M., et al. Histologic tumor type is an independent prognostic parameter in esophageal cancer: Lessons from more than 1,000 consecutive resections at a single center in the Western world. Ann. Surg. 2001; 234: 360-367.

103. Wijnhoven B.P.L., Tran K.T.C., Esterman A., et al. An evaluation of prognostic factors and tumor staging of resected carcinoma of the esophagus. Ann. Surg. 2007; 245: 717-725.

104. Ancona E., Cagol M., Epifani M., et al. Surgical complications do not affect longterm survival after esophagectomy for carcinoma of the thoracic esophagus and cardia. J. Amer. Coll. Surg. 2006; 203(5): 661-669.

105. Smithers B.M., Gotley D.C., Martin I., et al. Comparison of the outcomes between open and minimally invasive esophagectomy. Ann. Surg. 2007; 245: 232-240.

106. Millikan K.W., Silverstein J., Hart V., et al. A 15year review of esophagectomy for carcinoma of the esophagus and cardia. Arch. Surg. 1995; 130: 617-624.

107. Rizk N.P., Venkatraman E., Bains M.S., et al. American Joint Committee on Cancer Staging system does not accurately predict survival in patients receiving multimodality therapy for esophageal adenocarcinoma. J. Clin. Oncol. 2007; 25: 507-512.

108. Vint F.W. Malignant Disease in the Natives of Kenya. Lancet. 1935; 14: 628.

109. Nevill G.E.A. Cancer of the oesophagus. East Afr. Med. J. 1961; 38: 515-524

110. Ahmed N. Geographical incidence of oesophageal cancer in West Kenya. East Afr. Med. J. 1966; 43(7): 235-248.

111. Cook P. Cancer of the oesophagus in Africa. Brit. J. Cancer. 1971; 25: 853-880.

112. Gatei D.G., Odhiambo P.A., Orinda D.A., et al. Retrospective study of carcinoma of the oesophagus in Kenya. Cancer Res. 1978; 38: 303-307.

113. Zhang Z.X., Li B.Y. and Jin S.S. Epidemiologic trends of esophageal cancer in Linxian. Shi Guan Gang. Zhi Yan Fiu-Lixian. 1990; 1: 1-14.

114. Cancer Incidence Report, Nairobi 2000-2002, Nairobi Cancer Registry, 2006.

115. White R.E., Mutuma G.Z., Buckner S.B., et al. Esophageal Dysplasia in Asymptomatic Residents of Western Kenya: Interim Results of a Cytologic and Endoscopic Screening Program. Gastroenterol. 2004; 126 (Suppl 2): A24. 